\title{
Synthesis, Characterization, and Use of Novel Bimetal Oxide Catalyst for Photoassisted Degradation of Malachite Green Dye
}

\author{
K. L. Ameta, ${ }^{1}$ Neema Papnai, ${ }^{1}$ and Rakshit Ameta ${ }^{2}$ \\ ${ }^{1}$ Department of Chemistry, Faculty of Arts, Science and Commerce, Mody Institute of Technology and Science, \\ Lakshmangarh, Rajasthan 332311, India \\ ${ }^{2}$ Department of Chemistry, Pacific College of Basic \& Applied Sciences, PAHER University, Udaipur, Rajasthan 313024, India
}

Correspondence should be addressed to K. L. Ameta; klameta77@yahoo.co.in

Received 27 November 2013; Revised 22 March 2014; Accepted 22 March 2014; Published 30 April 2014

Academic Editor: Tong Lin

Copyright (C) 2014 K. L. Ameta et al. This is an open access article distributed under the Creative Commons Attribution License, which permits unrestricted use, distribution, and reproduction in any medium, provided the original work is properly cited.

\begin{abstract}
This work reports a simple, novel, and cost effective synthesis of nanobimetal oxide catalyst using cerium and cadmium nitrates as metal precursors. The cerium-cadmium oxide nanophotocatalyst was synthesized by coprecipitation method and characterized by X-ray powder diffraction method to analyze the particle size. XRD study reveals a high degree of crystallinity and $28.43 \mathrm{~nm}$ particle size. The photocatalytic efficiency of the synthesized nanobimetal catalyst was examined by using it for the photocatalytic degradation of malachite green dye. Experiments were conducted to study the effect of various parameters, such as the $\mathrm{pH}$ of the dye solution, concentration of dye, amount of catalyst, and light intensity on the rate of dye degradation. The progress of the dye degradation was monitored spectrophotometrically by taking the optical density of the dye solution at regular intervals. Experimental results indicate that the dye degrades best at $\mathrm{pH} 8.0$ with light intensity $600 \mathrm{Wm}^{-2}$ and catalyst loading $0.03 \mathrm{~g} / 50 \mathrm{~mL}$ of dye solution. The rate constant for the reaction was $7.67 \times 10^{-4} \mathrm{~s}^{-1}$.
\end{abstract}

\section{Introduction}

Clean water is a vital commodity, as it is a prerequisite for life. An adequate water supply in both quantity and quality is essential to human existence [1]. But one of the most serious threats related to water is the accumulation of nonbiodegradable and toxic compounds in the ecosystem leading to the degradation of the quality of water $[2,3]$. Due to the nature of various chemical processing of textiles, large volume of wastewater with numerous pollutants is discharged $[4,5]$. Photocatalysis has been considered and proved as a cost effective alternate for the purification of dyecontaining wastewater [6-10]. Studies have demonstrated that photocatalysis can be used to destroy dye compounds using semiconductor photocatalysts under light irradiation. The photocatalysts are able to photosensitize the complete mineralization of a wide range of compounds, like dyes, phenols, and pharmaceutical drugs, without producing harmful by-products at near room temperature and pressure [11-13].

Lately, there have been extensive studies done by researchers around the globe on many photocatalytic systems
(UV/semiconductors) since they have been found to be very effective in degrading various organic dyes. Many catalysts like $\mathrm{TiO}_{2}, \mathrm{ZnO}, \mathrm{ZrO}_{2}, \mathrm{WO}_{3}, \mathrm{Fe}_{2} \mathrm{O}_{3}, \mathrm{CeO}_{2}, \mathrm{CdS}$, and $\mathrm{ZnS}$ have been attempted for the photocatalytic degradation of a wide variety of environmental contaminants [14-21]. Studies have also demonstrated that bimetal catalyst has advantage of low metal leaching during the catalytic reaction, avoiding secondary metal contamination to the treated wastewater [22].

With this view, the present study was planned to investigate the degradation of malachite green dye with photocatalytic system using bimetal oxide. For this, a novel bimetal nanophotocatalyst, that is, cerium-cadmium oxide, was synthesized and the effect of different parameters such as $\mathrm{pH}$ of the dye solution, concentration of dye, the amount of catalyst, and intensity of visible light on the rate of dye degradation with cerium-cadmium oxide were assessed. Since sunlight is an abundantly available natural energy source, its energy can be conveniently exploited for the irradiation of semiconductor material. The kinetics of the 
absorption process was evaluated to study the absorption mechanism of dye molecule.

\section{Experimental}

2.1. Synthesis of Bimetal Cerium-Cadmium Oxide. The synthesis of novel cerium-cadmium oxide was achieved by coprecipitation method. The mixed oxide was prepared by adding an aqueous solution of $1 \mathrm{M} \mathrm{NaOH}$ dropwise to the aqueous solution of $0.1 \mathrm{M}$ of both $\mathrm{Ce}\left(\mathrm{NO}_{3}\right)_{3} \cdot 6 \mathrm{H}_{2} \mathrm{O}$ and $\mathrm{Cd}\left(\mathrm{NO}_{3}\right)_{2} \cdot 4 \mathrm{H}_{2} \mathrm{O}$ with concurrent stirring. The $\mathrm{pH}$ of the mixed solution was adjusted at different $\mathrm{pH}$ in the alkaline range, but at $\mathrm{pH} 8$, complete precipitation was observed so the $\mathrm{pH} 8$ was maintained. After 4 hours of continuous stirring, the precipitate was filtered and repeatedly washed with deionized water. The residue was dried in an oven at $110^{\circ} \mathrm{C}$ overnight and then grounded in acetone with mortar and pestle. The powder received was then calcined at $500^{\circ} \mathrm{C}$ for 4 hours under static air in a muffle furnace.

\subsection{Characterization of the Synthesized Bimetal Cerium-} Cadmium Oxide. X-ray powder diffraction study was performed to establish the phase purity and crystalline nature of the synthesized bimetal oxide by X-ray diffractometer. The particle size of the synthesized photocatalyst was determined using the Scherrer equation.

2.3. Photocatalytic Degradation of Dye. A stock solution of malachite green (structure is shown in Figure 1) of 1.0 $\times 10^{-3} \mathrm{M}$ was prepared by dissolving $0.365 \mathrm{~g}$ of malachite green in $1000 \mathrm{~mL}$ of double distilled water. The absorption maximum of the dye was determined with the help of a spectrophotometer (Systronics Model 106).

Photocatalytic degradation of malachite green dye was studied by exposing the dye solution to light in the presence of synthesized nanobimetal oxide. For irradiation purpose, $200 \mathrm{~W}$ tungsten lamp (Philips) was used. The intensity of light was measured by solar power meter (TENMARS model TM 207). A water filter was used to cut off thermal radiation. The $\mathrm{pH}$ of the solution was measured by a digital $\mathrm{pH}$ meter (Systronics Model 324) and the desired $\mathrm{pH}$ was adjusted by the addition of $0.1 \mathrm{~N}$ sodium hydroxide and $0.1 \mathrm{~N}$ sulphuric acid solutions. The progress of photocatalytic degradation of the dye was monitored by withdrawing definite quantity of the reaction mixture at regular time intervals and measuring the absorbance by the UV-VIS spectrophotometer at a maximum wavelength $\left(\lambda_{\max }=620 \mathrm{~nm}\right)$. Additional experiments were conducted to verify that the observed reaction was indeed photocatalysis. For this, the dye solution was irradiated with solar/UV light without adding photocatalyst and with photocatalyst in the absence of solar/UV light.

\section{Results and Discussion}

3.1. Characterization of the Synthesized Bimetal CeriumCadmium Oxide. The XRD pattern of cerium-cadmium oxide is shown in Figure 2. The graph has been plotted between intensity (cycles per second) and $2 \theta$ values (in

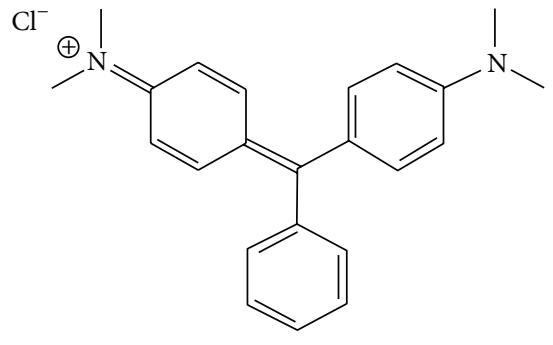

FIGURE 1: Chemical structure of Malachite green.

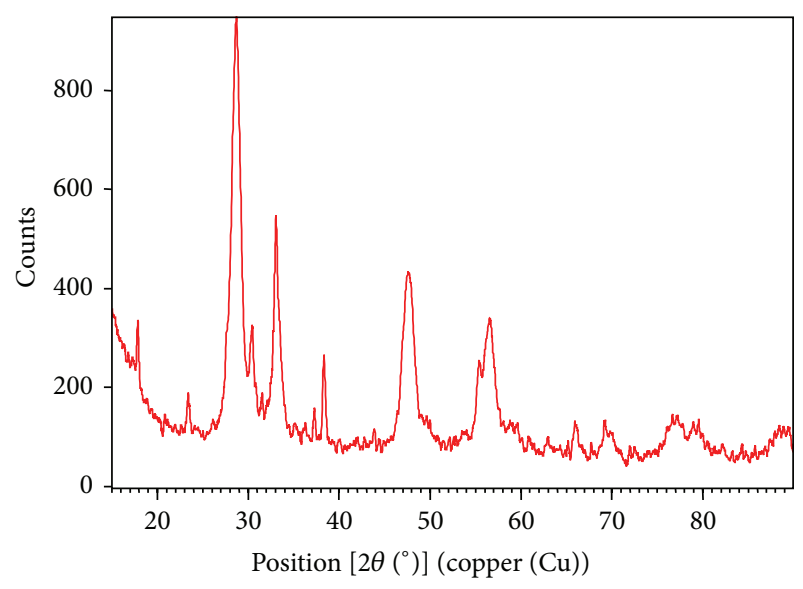

FIGURE 2: X-ray powder diffraction pattern of cerium-cadmium oxide.

degrees). For general consideration, $2 \theta$ values range from 20 to $80^{\circ}$, as the characteristic peaks for ternary oxides of cerium and lanthanum with transition metals appear in the same range. The synthesized catalyst is in nanoform $(28.43 \mathrm{~nm})$ as determined by the Scherrer equation.

3.2. Photocatalytic Degradation of Dye Using Nanosized Bimetal Oxide. A $2.0 \mathrm{~mL}$ of the solution was taken out from the reaction mixture, which contains dye and ceriumcadmium oxide at regular time interval and absorbance was measured spectrophotometrically at $\lambda_{\max }=620 \mathrm{~nm}$. It was observed that the absorbance of the solution decreases with increasing time intervals showing thereby that the concentration of the dye decreases with increasing time of exposure. A plot of $2+\log$ O.D. versus time was linear and follows first-order kinetics. The rate constant was calculated by using the expression, $k=2.303 \times$ Slope. The rate constant for the reaction was $7.67 \times 10^{-4} \mathrm{~s}^{-1}$.

The typical run for dye degradation is given in Table 1 and graphically represented in Figure 3.

Attempts have been made to study the effect of $\mathrm{pH}$ on the rate of dye degradation under visible light irradiation as $\mathrm{pH}$ plays an important role both in the characteristics of textile wastewater and the generation of hydroxyl radicals. Hence, photodegradation process was examined at $\mathrm{pH}$ values from 6 to 10 . The effect of $\mathrm{pH}$ on the rate of dye degradation is reported in Figure 4. 
TABLE 1: A typical run of malachite green dye degradation using cerium-cadmium oxide ${ }^{\mathrm{a}}$.

\begin{tabular}{lcc}
\hline Time (min.) & Optical Density (O.D.) & $2+\log$ O.D. \\
\hline 0.00 & 1.240 & 2.0934 \\
20.00 & 0.560 & 1.7482 \\
40.00 & 0.213 & 1.3284 \\
60.00 & 0.077 & 0.8865 \\
80.00 & 0.036 & 0.5563 \\
& $k=7.67 \times 10^{-4} \mathrm{~s}^{-1}$ & \\
\hline
\end{tabular}

${ }^{a}$ Reaction conditions: dye concentration $=2.50 \times 10^{-5} \mathrm{M}$, light intensity $=$ $600 \mathrm{Wm}^{-2}$, cerium-cadmium oxide $=0.03 \mathrm{~g}$ in $50 \mathrm{~mL}$ dye solution, and $\mathrm{pH}$ $=8$.

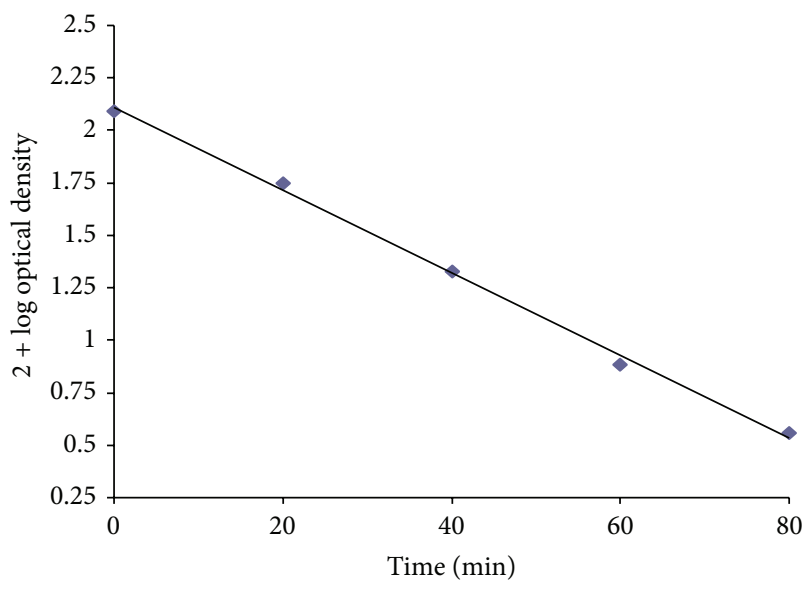

FIgURE 3: Plot of $2+\log$ O.D. verses time for a typical run.

\subsection{Effect of Different Variables on Photocatalytic Degradation of Dye}

3.3.1. Effect of $p H$. In both acidic and alkaline $\mathrm{pH}$, it seems to increase the percentage degradation of the dye. As observed, the rate of reaction increased with increasing $\mathrm{pH}$ of the solution up to $\mathrm{pH}$ 8.0. However, a further increase in $\mathrm{pH}$ of solution resulted in a decreased reaction rate. An increase in the rate of photocatalytic degradation of malachite green with increase in $\mathrm{pH}$ may be due to the generation of more - OH radicals, which are produced from the reaction between ${ }^{-} \mathrm{OH}$ ions and hole $\left(\mathrm{h}^{+}\right)$of the semiconductor. Above $\mathrm{pH}$ 8.0 , a decrease in the rate of photocatalytic degradation of the dye was observed, which may be due to the fact that the cationic form of malachite green converts in its natural form, which faces no attraction towards the negatively charged semiconductor surface due to adsorption of ${ }^{-} \mathrm{OH}$ ions.

3.3.2. Effect of Concentration of Dye. The effect of dye concentration on the rate of dye degradation was studied by varying the concentration of dye from $1.50 \times 10^{-5}$ to $4.50 \times$ $10^{-5} \mathrm{M}$ (Figure 5). It can be seen that rate of dye degradation increased with increasing the dye concentration up to $2.50 \times$ $10^{-5} \mathrm{M}$; after that the rate of photodegradation decreased with further increase in the dye concentration. The possible explanation for this behavior is that as the concentration of

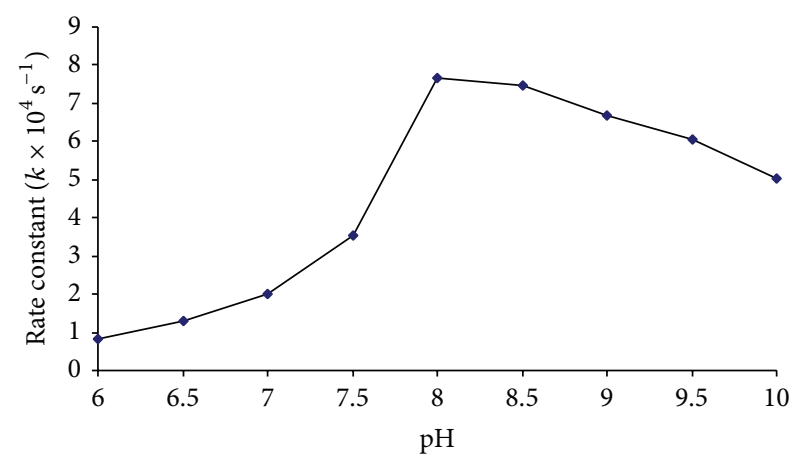

FIGURE 4: Effect of $\mathrm{pH}$ on degradation of malachite green. Reaction conditions: dye concentration $=2.50 \times 10^{-5} \mathrm{M}$, light intensity $=$ $600 \mathrm{Wm}^{-2}$, and cerium-cadmium oxide $=0.03 \mathrm{~g}$ in $50 \mathrm{~mL}$ dye solution.

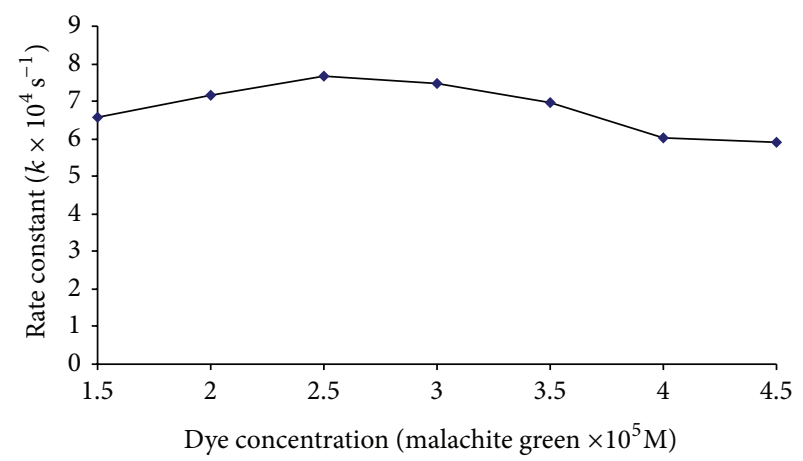

FIgURE 5: Effect of dye concentration on degradation of malachite green. Reaction conditions: cerium-cadmium oxide $=0.03 \mathrm{~g}$ in $50 \mathrm{~mL}$ dye solution, $\mathrm{pH}=8$, and light intensity $=600 \mathrm{Wm}^{-2}$.

dye was increased, more dye molecules were available for excitation and energy transfer and, hence, an increase in the rate was observed, but, on further increase in concentration, dye starts acting as a filter for the incident light and will not permit the light intensity to reach the semiconductor surface.

3.3.3. Effect of Semiconductor Amount. The effect of nanophotocatalyst loading on the rate of dye degradation has been examined by varying its amount from 0.02 to $0.08 \mathrm{~g} / 50 \mathrm{~mL}$ of the dye solution. The results are presented in Figure 6.

It was observed that the rate of dye degradation increases rapidly with the increase in the amount of photocatalyst from 0.02 to $0.03 \mathrm{~g} / 50 \mathrm{~mL}$ of the dye. With further increase in the amount of photocatalyst from 0.03 to $0.08 \mathrm{~g}$, the rate of dye degradation decreases. This can be rationalized in terms of availability of active sites on catalyst surface and light penetration of photo activating substance into the suspension. The decreased degradation rate at higher catalyst loading may be due to deactivation of activated molecules by collision with ground state molecules.

Hence, an optimum catalyst has to be added in order to avoid unnecessary excess catalyst and also to ensure total 


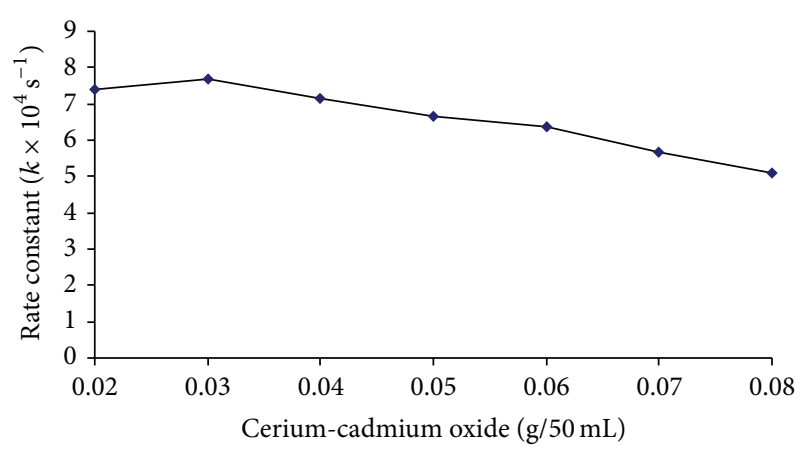

FIgURE 6: Effect of amount of cerium-cadmium oxide on degradation of malachite green. Reaction conditions: dye concentration $=$ $2.50 \times 10^{-5} \mathrm{M}$, light intensity $=600 \mathrm{Wm}^{-2}, \mathrm{pH}=8$.

absorption of solar light photons for efficient photomineralisation.

3.3.4. Effect of Light Intensity. The effect of light intensity on the rate of reaction was also studied. The observations are summarized in Figure 7. It was observed that the rate constant increased with increasing light intensity from 200 up to $600 \mathrm{Wm}^{-2}$ because on increasing the light intensity, the number of photons striking per unit area of reaction mixture will also increase. This will result in a corresponding increase in the rate of degradation of malachite green. Small decrease in the rate on further increasing light intensity may be due to some thermal or side reactions.

Mechanism. On the basis of these observations, a tentative mechanism for photocatalytic degradation of malachite green may be proposed as

$$
\begin{aligned}
& \text { (1) }{ }^{1} \mathrm{MG}_{0} \stackrel{h v}{\longrightarrow} \mathrm{MG}_{1} ; \\
& \text { (2) }{ }^{1} \mathrm{MG}_{1} \stackrel{\mathrm{ISC}}{\longrightarrow}{ }^{3} \mathrm{MG}_{1} ; \\
& \text { (3) } \mathrm{SC} \stackrel{h v}{\longrightarrow} \mathrm{e}^{-}(\mathrm{CB})+\mathrm{h}^{+}(\mathrm{VB}) ; \\
& \text { (4) } \mathrm{e}^{-}+\mathrm{O}_{2} \longrightarrow \mathrm{O}_{2}^{-} ; \\
& \text {(5) } \mathrm{O}_{2}^{-}{ }^{-}+{ }^{3} \mathrm{MG}_{1} \longrightarrow \text { Leuco MG; } \\
& \text { (6) Leuco } \mathrm{MG} \longrightarrow \text { Products. }
\end{aligned}
$$

Malachite green (MG) absorbs radiations of suitable wavelength and gives rise to its first excited singlet state. Then it undergoes intersystem crossing (ISC) to give the triplet state of the dye. On the other hand, the semiconducting ceriumcadmium oxide (SC) also utilizes the radiant energy to excite its electron from the valence band to the conduction band. This electron will be abstracted by an oxygen molecule (dissolved oxygen) generating superoxide anion radical $\left(\mathrm{O}_{2}{ }^{-}\right)$. This anion radical will reduce the dye malachite green to its leuco form, which may ultimately degrade to products. It was also confirmed that this degradation proceeds through reduction and not oxidation as the rate of degradation was not affected appreciably in the presence of hydroxyl radical scavenger (2-propanol).

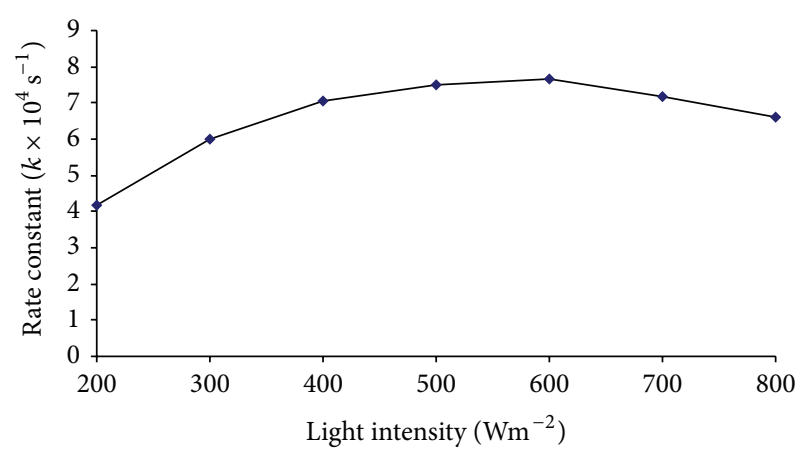

FIGURE 7: Effect of light intensity on degradation of malachite green. Reaction conditions: dye concentration $=2.50 \times 10^{-5} \mathrm{M}, \mathrm{pH}=8$, cerium-cadmium oxide $=0.03 \mathrm{~g}$ in $50 \mathrm{~mL}$ dye solution.

\section{Conclusion}

Easy, simple, fast, and low cost synthesis of novel nanosized cerium-cadmium oxide and its characterization by XRD were studied in this research paper. The particle size of the synthesized bimetal oxide is $28.43 \mathrm{~nm}$. From the nanotechnology point of view, this is a significant advancement to synthesize nanosized cerium-cadmium bimetal oxide. Based on this study, some other nanophotocatalysts may be synthesized in the future. Also, in this paper, we reported the photocatalytic activity of the synthesized nanoparticles. The optimum reaction conditions of dye degradation with cerium-cadmium oxide were experimentally determined. The photochemical degradation of dye follows first-order kinetics. The synthesized bimetal oxide may be used for the degradation of some other dyes.

\section{Conflict of Interests}

The authors declare that there is no conflict of interests regarding the publication of this paper.

\section{Acknowledgment}

The authors greatly acknowledge SAIF Chandigarh, India, for the XRD facility.

\section{References}

[1] G. M. Carr and J. P. Neary, Water Quality for Ecosystem and Human Health, United Nations Environment Programme Global Environment Monitoring System (GEMS)/Water Programme, Canada, 2nd edition, 2008.

[2] M. Palaniappan, P. H. Gleick, L. Allen, M. J. Cohen, J. ChristianSmith, and C. Smith, Clearing the Waters - A Focus on Water Quality Solutions, UNON, Publishing Services Section, Nairobi, United Nations Environment Programme, 2010.

[3] O. B. Akpor and M. Muchie, "Remediation of heavy metals in drinking water and wastewater treatment systems: processes and applications," International Journal of Physical Sciences, vol. 5, no. 12, pp. 1807-1817, 2010. 
[4] M. M. Rahman, Q. H. Bari, N. Mohammad, A. Ahsan, H. R. Sobuz, and A. M. Uddin, "Characterization of rice husk carbon produced through simple technology," Advances in Materials Science and Application, vol. 2, no. 1, pp. 25-30, 2013.

[5] B. R. Babu, A. K. Parande, S. Raghu, and T. P. Kumar, "Cotton textile processing: waste generation and effluent treatment," Journal of Cotton Science, vol. 11, no. 3, pp. 141-153, 2007.

[6] R. Tafer and A. Boulkamh, "Direct photolysis of an azo-dye, Erichrome Black T," Research Journal of Applied Sciences, vol. 3, pp. 339-344, 2008.

[7] R. Aplin and T. D. Waite, "Comparison of three advanced oxidation processes for degradation of textile dyes," Water Science and Technology, vol. 42, no. 5-6, pp. 345-354, 2000.

[8] M. H. Habibi, M. N. Esfahani, and T. A. Egerton, "Photochemical characterization and photocatalytic properties of a nanostructure composite $\mathrm{TiO}_{2}$ film," International Journal of Photoenergy, vol. 2007, Article ID 13653, 8 pages, 2007.

[9] A. F. Martins, M. L. Wilde, and C. da Silveira, "Photocatalytic degradation of brilliant red dye and textile wastewater," Journal of Environmental Science and Health A: Toxic/Hazardous Substances and Environmental Engineering, vol. 41, no. 4, pp. 675685, 2006.

[10] O. Zahraa, S. Maire, F. Evenou et al., "Treatment of wastewater dyeing agent by photocatalytic process in solar reactor," International Journal of Photoenergy, vol. 2006, Article ID 46961, 9 pages, 2006.

[11] S. K. Kansal, N. Kaur, and S. Singh, "Photocatalytic degradation of two commercial reactive dyes in aqueous phase using nanophotocatalysts," Nanoscale Research Letters, vol. 4, no. 7, pp. 709-716, 2009.

[12] S. Chakrabarti and B. K. Dutta, "Photocatalytic degradation of model textile dyes in wastewater using $\mathrm{ZnO}$ as semiconductor catalyst," Journal of Hazardous Materials, vol. 112, no. 3, pp. 269278, 2004.

[13] S. K. Kansal, A. Hassan Ali, and S. Kapoor, "Photocatalytic decolorization of biebrich scarlet dye in aqueous phase using different nanophotocatalysts," Desalination, vol. 259, no. 1-3, pp. 147-155, 2010.

[14] F. Zhang, J. Zhao, L. Zang et al., "Photoassisted degradation of dye pollutants in aqueous $\mathrm{TiO}_{2}$ dispersions under irradiation by visible light," Journal of Molecular Catalysis A: Chemical, vol. 120, no. 1-3, pp. 173-178, 1997.

[15] T. K. Tan, P. S. Khiew, W. S. Chiu et al., "Photodegradation of phenol red in the presence of $\mathrm{ZnO}$ nanoparticles," World Academy of Science, Engineering and Technology, vol. 55, pp. 791-796, 2011.

[16] H. R. Pouretedal and M. Hosseini, "Bleaching kinetic and mechanism study of congo red catalyzed by $\mathrm{ZrO}_{2}$ nanoparticles prepared by using a simple precipitation method," Acta Chimica Slovenica, vol. 57, no. 2, pp. 415-423, 2010.

[17] B. Neppolian, H. C. Choi, S. Sakthivel, B. Arabindoo, and V. Murugesan, "Solar/UV-induced photocatalytic degradation of three commercial textile dyes," Journal of Hazardous Materials, vol. 89, no. 2-3, pp. 303-317, 2002.

[18] L. Bharadwaj, M. Bhardwaj, and M. K. Sharma, "An analysis of $\mathrm{Fe}_{2} \mathrm{O}_{3}$ assisted photocatalytic degradation of Congo Red dye," Toxicological and Environmental Health Sciences, vol. 4, no. 1, pp. 62-69, 2012.

[19] P. Ji, J. Zhang, F. Chen, and M. Anpo, "Study of adsorption and degradation of acid orange 7 on the surface of $\mathrm{CeO}_{2}$ under visible light irradiation," Applied Catalysis B: Environmental, vol. 85, no. 3-4, pp. 148-154, 2009.
[20] L. L. Ma, H. Z. Sun, Y. G. Zhang et al., "Preparation, characterization and photocatalytic properties of CdS nanoparticles dotted on the surface of carbon nanotubes," Nanotechnology, vol. 19, no. 11, Article ID 115709, 2008.

[21] J. S. Hu, L. L. Ren, Y. G. Guo et al., "Mass production and high photocatalytic activity of ZnS nanoporous nanoparticles," Angewandte Chemie International Edition, vol. 117, no. 8, pp. 1295-1299, 2005.

[22] A. C. K. Yip, F. L. Y. Lam, and X. Hu, "Novel bimetallic catalyst for the photo-assisted degradation of Acid Black 1 over a broad range of pH," Chemical Engineering Science, vol. 62, no. 18-20, pp. 5150-5153, 2007. 

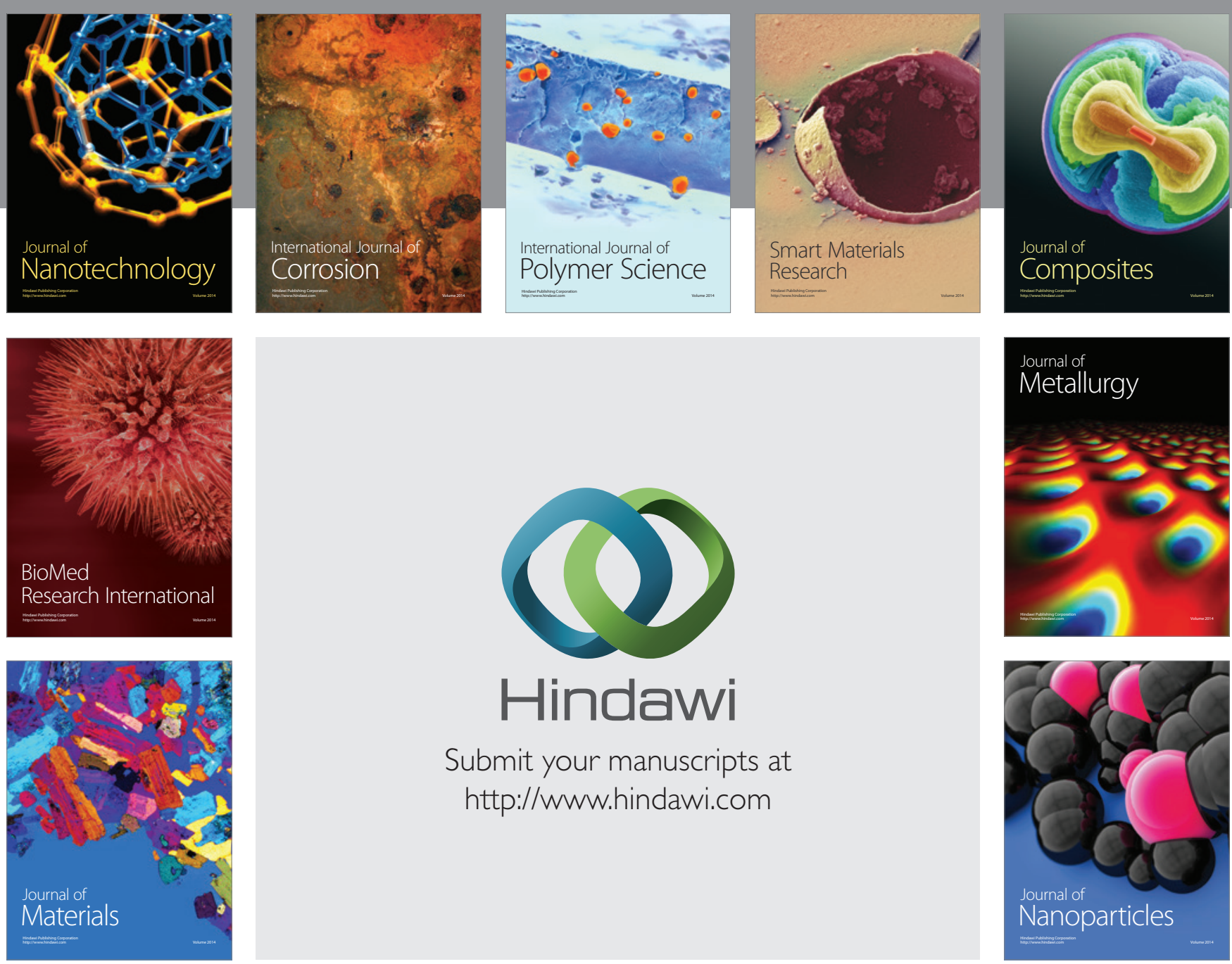

Submit your manuscripts at http://www.hindawi.com
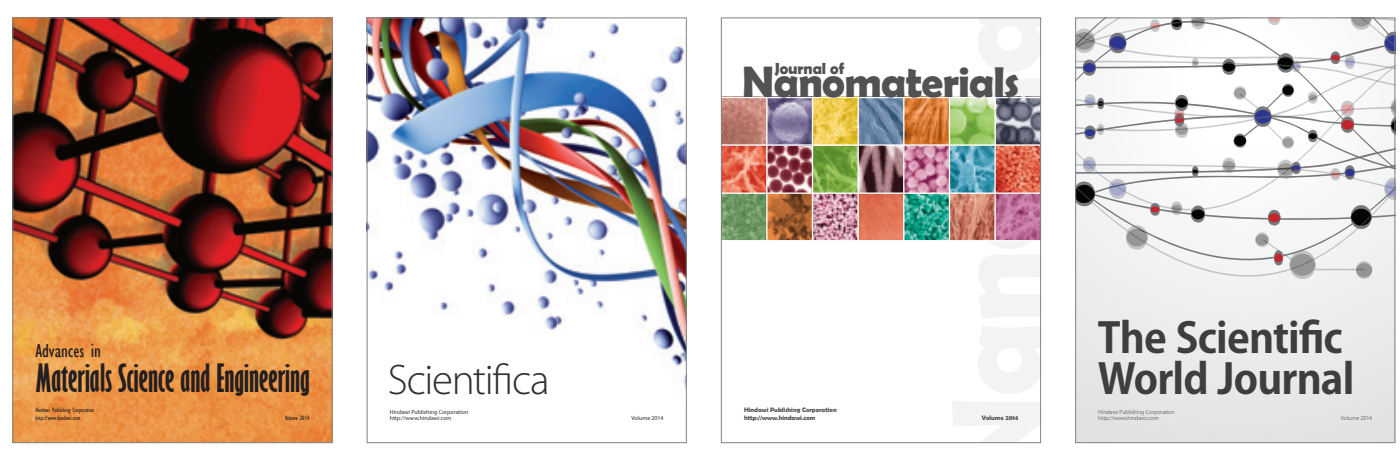

\section{The Scientific World Journal}
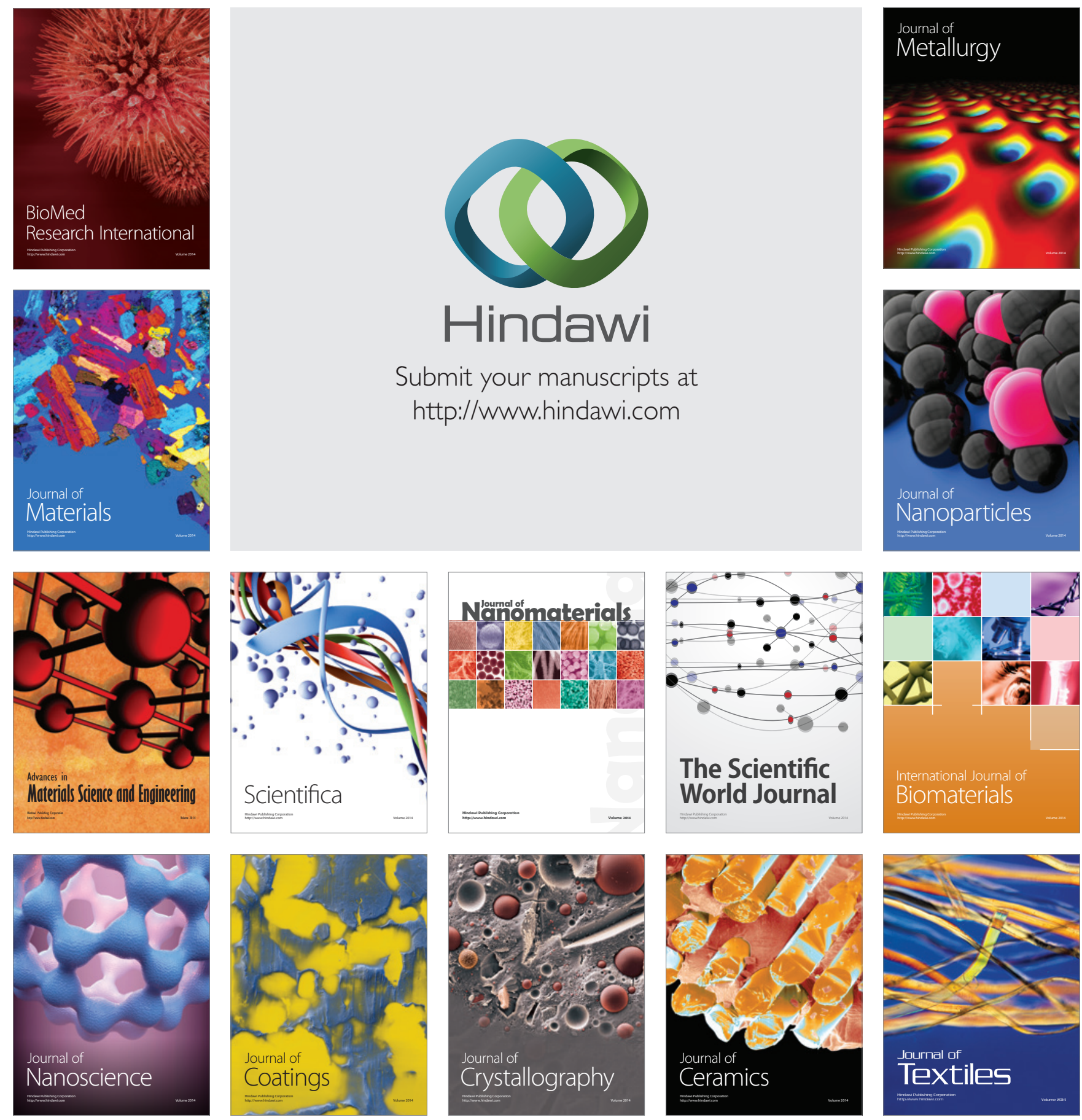